\title{
Albania - Greece Agreement on Setting Maritime Boundaries, According to International Law
}

\author{
Kasëm Cenaj
}

Vlorë, Albania

Doi:10.5901/ajis.2015.v4n3p143

\section{Abstract}

On March 19, 2009, in Tirana has ended the negotiations and initialed the "Agreement between Greece and Albania on the delimitation of continental shelf and other maritime areas belonging, according to the International Law". This agreement was signed in Tirana, from the two respective Ministers of Foreign Affairs, on April 27, 2009. Since its introduction, the agreement states that "the maritime borders between Albania and Greece, will be determined on the basis of equity distance expressed by the medium line". Merits of the case would require study of the complete file of the agreement, including the texts of the agreement in three languages: English, Greek and English, as well as the maps of the agreement, which has so far has not been made public. Emphasize that Albania has ratified UNCLOS, on June 23, 2003, while Greece on July 21, 1995. This agreement was ratified by the Albanian parliament, but was unapproved by the Albanian Constitutional Court, arguing that conflicted with the Constitution of Albania and the UN Third Convention of the International Law of the Sea of the year 1982. The paper will address the importance of signing this agreement, in the context of historical, economic and geopolitical, as well as losses or profits caused by its unapproval.

Keywords: agreement, maritime boundaries, ratification, continental shelf, territorial waters.

\section{The Importance of the Agreement}

This agreement is important because it deals with the sharing of the waters between the two countries and thus to protect the interests of customs, fiscal, sanitary, immigration, self-defense against the imminent danger, prevention of pollution in the sea, especially oil, reserving the right to fishing for the protection of archaeological and historical objects originally discovered in the sea of robbery or illegal trade in their particular geopolitical importance. The Convention allows the coastal State to exercise the necessary control over the area in order to avoid violation of state laws on their territory or territorial waters.

In the continental shelf, the coastal State exercises exclusive rights over mineral patrimony of the seabed and subsoil. Exclusive Economic Zone regime is not the same, or similar, with territorial waters. Here, the coastal State exercises sovereign rights, in the springs of living and non-living, but the passage of foreign ships, civilian and military, free, and in the territorial waters of the state exercises full sovereignty.

\subsection{The historical significance}

Although there was a bilateral agreement, the regime and water borders between Albania and Greece are defined by the Protocol of Florence, year of 1926, and they are set in a time when sea issues had not been resolved definitively. The Article 10 of this Protocol, says, quote that "various issues will arise for determining the boundary line, which are not provided for by this Protocol shall be the subject of direct agreements between governments." So in principle, a matter that has not been treated in its normal time to be treated at this time.

As is known, the decision of the conference of ambassadors in 1913, reaffirmed by the Protocol of Florence, gives an indication of the character of principle on the direction that would follow the border line, which would separate the Albanian waters by Greek ones in the canal close to Corfu. This line should be among the Strait watch, being at any point of its equidistant from the shores face to face. On this basis, if Albania and Greece, determined independently water boundary line, the line that was essentially the same and was met and respected by both parties to the present day. Nearly one hundred years the Barketa rock was never counted as an element affecting the dividing line removal. Why was the maritime border between Albania and Greece, and the International Court of Justice in its decision dated 12.15.1949, for the Corfu incident found that the UK, with its vessels, on November 12 to 13, 1946, violated the 
sovereignty of Albania. This Court administered as evidence of navigation maps and navigation logs.

The determination of criteria based on the territorial waters of the distance and therefore does not present difficulties in oceanic or marine areas with broadband spreading. But the difficulties arise when it comes to determining their coast between the states of complying or facing each other, as in the case with Greece. Deviation from the dividing line real-border water of Albania, in the northern part of the Strait of Corfu, mainly in the Gulf of Saranda, and in the narrowest part of it, is clearly distinguished when comparing, the new division by geographical coordinates of the agreement on the maritime border Greece (although such a map is not made public yet) with the navigation map, use the English edition by British warships on October 22, 1946. The national law for delimitation of the year 2001 provides that the sovereignty of the Republic of Albania spreads in space air above the territorial waters and the bed and subsoil of these waters and the plateau (shelf) for the purpose of continental research and exploitation of its natural resources ${ }^{1}$. With the adoption of the new law in $2008^{2}$, were abolished all previous laws on the border, and other provisions contrary to this law. These are the laws and ordinances exempted, amended and in force in the Republic of Albania since the year 1970 until today.

The delimitation (division) of continental shelf, presents problems especially in those cases where countries stand face to face and when the sea is relatively shallow, which allows sharing of all continental bedding and this especially for the most part of the Adriatic Sea. The delimitation of the continental bed presents limitations for neighboring countries, provided by Article 83 of UNCLOS Convention. ${ }^{3}$. This article contains rules compromise, with an emphasis on bilateral negotiations to reach a fair solution, although in practice the states apply the two principles: the equity distance and justice.

\subsection{The economic importance}

In projects financed by the Albanian government, but also with foreign funding, in early years of this decade, the Port of Vlore, which together with that of Durres, would be the front of the entrance to $8^{\text {th }}$ Corridor, which will pass by Macedonia, Bulgaria and Turkey, but also the place where AMBO pipeline will finish. This will lead to a departure of Greece and the rest of her a pocket in European corridors, and consequently, loss of weight as a springboard for goods coming from East to West and vice versa and bridgehead for them. Facing the prospect that it will reduce the economic burden, and consequently political Greece in the region, the governments of the country, made the highway "Egnatia Odhos". This highway traverses across northern Greece and now ends at the port of Igoumenitsa. Also in cooperation with the Russians, it approved construction of the Burgas - Aleksandropullos pipeline and in project is the Aleksandropullos Igoumenitsa branching. All these parallel projects which are to end their automatically weaken the $8^{\text {th }}$ Corridor, which gave developing of Albania and the Albanian regions, as funders foreign, are interested to throw money at a project parallel to it already on the verge of completion that made the Greeks. Also, the south of Italy, so eager for Libyan gas, can be supplied to the port of Igoumenitsa, which may arise plants planned to be built in Vlora, or to receive Russian gas through offshore pipeline, which will pass in waters that are designated in the agreement.

With the introduction of the territorial waters of Greece as a wedge between Italy and Albania, cargo ships coming from the Suez Canal, as well as gas and oil carrier, will avoid the port of Vlora and Durres, and will stop at the port of Igoumenitsa, from they will be distributed throughout the Balkans and Central Europe.

\subsection{The geopolitical importance}

The part designed into the agreement (with an area of $300 \mathrm{~km} 2$ ) starting from 2012, therefore, not very far in time, will be one of the nodes of the grid of the "pure" and will be a bridge between the Balkan Peninsula and the rest of Europe, for

\footnotetext{
1 Predicting the law no. 8771, dated April 19, 2001, entered into force on April 19, 2001 "On the state border of the Republic of Albania", which repealed the Decree Law no. 4650, dated March 9, 1970 "For the confine of Albania" with subsequent amending ordinances. Alongside this new law on state border it was adopted the Law no. 8772, dated April 19, 2001 "For the protection and control of the state border of the Republic of Albania".

${ }^{2}$ Law no. 9861, dated January 24, 2008 "On the control and supervision of the state border" when in the Chapter IX, the transitional provisions, Article 53, the exemptions: "Law no. 8771, dated. 04.19.2001 "On the state border of the Republic of Albania" no. 8772, dated April 19, 2001 "For the protection and control of the state border of the Republic of Albania" and any other provision contrary to this law are exempted. "This law came into force on March 01, 2008.
}

${ }^{3}$ UNCLOS - UN Convention on the Law of the Sea. 
the transmission of one of the most powerful engines of the world's industrialized power. It is the biggest project of production and distribution of energy futures, ever conducted, thanks to the cooperation of dozens of countries on three continents.

In a project initiated by French President Sarkozy, for the production of energy from renewable sources and infrastructure of the power distribution network to Europe, it noted that one of the branches crosses the channel of Otranto, in the Albanian maritime territory. It is precisely, that part of marine Albanian territory, located in the Ionian Sea, which according to the agreement between the two governments, Albanian and Hellenic, may soon pass the Greek state. If this agreement would be ratified, then Albania will fail to enjoy what belongs by "cake" big solar revolution, which will lead the economy of the future.

The initiative of the Union of Mediterranean countries for the production and distribution of renewable energy in the future is set to start in 2012. It is a publication of the Italian Navy July 25 of the last year. The article is illustrated with a map (Figure 1) in which all stations described the production of renewable energy in the Mediterranean countries and their European counterparts. In this map is also designed the entire power distribution network. Stations spread in all areas of the Sahara Desert and the Arabian Peninsula, are the ones that will produce mainly energy emitted from the sun. While in the northwestern part of Africa and the European continent observed output power stations by the wind.

Also on the map, there is the energy distribution network linking all stations with each other and permeates the countries concerned. One of the ramifications of the network which summarizes stations solar energy production, which is in Egypt, passing through the Mediterranean Sea, initially in Crete and then in mainland Greece. Precisely, this bifurcation addresses in northwestern Greece and Italy passing thrown into the waters of the lonian Sea. On the map it is clear that the project of solar energy revolution branching network that passes from Greece to southern Italy must pass in Albanian territorial waters. Waterfront area, where he will spend the accompanying energy network, coincides with those square kilometers which according to our agreement with the Hellenic Government, the Greek cross. Albanian government authorities and Hellenic never been associated with reason and strategy of this agreement. But you cut off this part of the sea Albanian territory, our country loses permanent financial income to be provided as a result of the passage of the network within the borders, while the latter cease to exist. This, after Albania will not have the privilege of being the beneficiary of this initiative the countries of the Mediterranean Union, an initiative which provides the fulfillment of energy needs of three continents in the future when the oil will probably be exhausted.

The project of French President Sarkozy to create a Mediterranean union that will encompass the needs of the Basin, where the most important are those energy is becoming increasingly and more realistic. After the meeting of 13 July last year, attended by 27 countries participating in the European Union as well as Algeria, Egypt, Israel, Jordan, Lebanon, Morocco, Mauritania, Syria, Tunisia, Turkey, Albania, Croatia, Bosnia-Herzegovina, Montenegro and the Palestinian Authority, as part of what will be in the future, in 2050, it seemed clear: "Farewell diesel and roads open to all sources of energy renovated, above all the solar one".

Sarkozy called on EU countries to launch and build the foundations of the revolution solar in the last ten years, from 2012 until 2020, when it will be necessary to prepare all infrastructures, in order to avoid being found by surprise by it even if it will not be the end of oil, it will resemble more the situation. In this context the start of a project to capture solar energy in the Sahara desert which will enter the wider context of TREC ${ }^{4}$ conceived and set in motion by the Club of Rome, the Hamburg Climate Protection Foundation NERC5.

I think that the line of the territorial sea is measured very unfair. Without appropriate measurements, we can be said that Saranda bay, fulfill the international legal criteria to be classified as historic bay or bay, but the removal of the baseline from Barketa rock, is completely unfair. In this case, we are dealing with a violation, as Greece calls this part of the archipelago rock starting to make measurements from the coast of this island. I think that these islands and rocks, does not constitute an archipelago. For archipelago, it means islands that make up a unity. It does not seem right that we can talk about an archipelago of Corfu and does not seem right to start the breadth, exactly starting from the edge of the rocks, which it is Barketa.

${ }^{4}$ TREC- Trans-Mediterranean Renewable Energy Cooperation

${ }^{5}$ NERC (National Energy Reasearch Center of Jordan). 


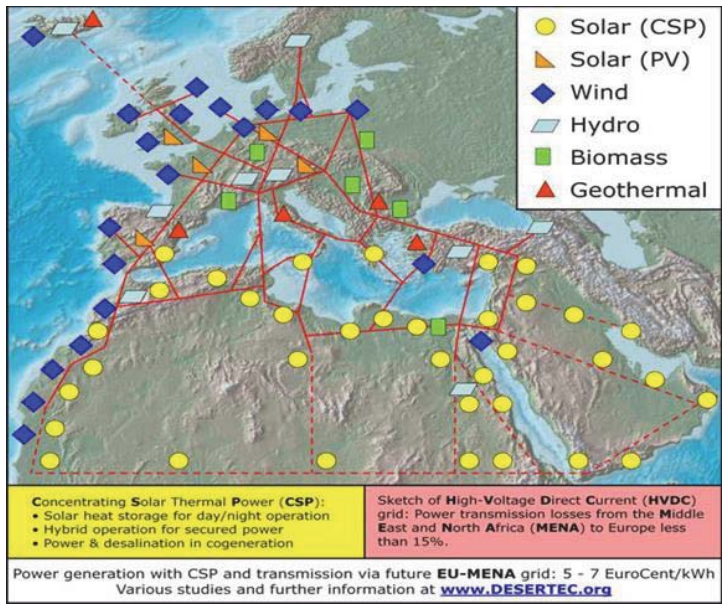

\section{Figure 1.}

\section{The Losses and Benefits}

With this agreement the Hellenic Republic would benefit in this case in three directions in the north (between Ngushtesës), in the west where there is space marine with Italy, in the south where it is natural universe water. While belongs only constraint facing the two countries, Italy and Albania.

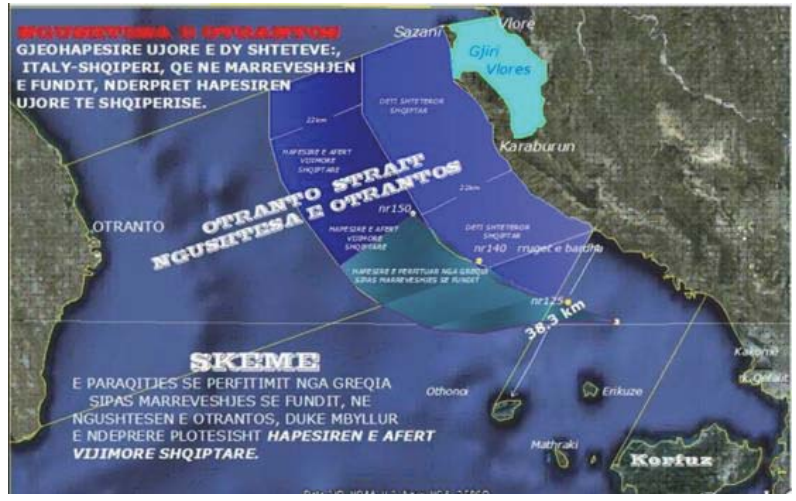

\section{Figure 2.}

Albania will lose more than $354.4 \mathrm{~km}$ square sea from the limits set under the agreement for the avoidance of marine waters and the continental shelf division. This is the conclusion of a group of geodesists experts, who managed via satellite format (numeric) to derive data on the length of lines in Albania and Greece riparian and aquatic areas that have benefited under the agreement of April 2009.

The measurements were calculated with a map in satellite format (digital) on a scale of 1: 100,000, where the agreement was thrown line, and from it received data for the length of the lines of the two states riparian and aquatic areas that are benefited. According to the Albanian coast line measurements $1 \mathrm{~km}$ and benefits around $10.2 \mathrm{~km} 2$ continental shelf marine waters, and riparian of $1 \mathrm{~km}$ of the Republic of Greece receives $17.2 \mathrm{~km} 2$ of continental shelf marine waters.

The agreement with Greece by geodesists means for determining the baseline can be used criteria related to the concept of the archipelago (Article 47 of the Convention), which enables the Greek use "the rock on the surface of the 
water ... point reference for the separation of surface water ", as used the Barketa rock.

\subsection{The loss in tourism}

Also Albanian ports lose their attraction as tourist ports for yachts. In the winter, Europeans vessels northern to Croatian ports or shelter in northern Italy. With the start of the summer season, down in the south of the Mediterranean, making stops supply in Greek ports, and it was thought that this function to take the Albanian ports in the future.

\section{The Decision of the Constitutional Court}

The announcement on the official website of the Court states "in the draft agreement in question, procedural and substantive infringement, which is inconsistent with the Constitution and Convention of the International Third UN for the Law of the Sea, year 1982 ". From the legal standpoint, it is important that the Court is not satisfied with an emphasis of procedural violations, then provides this competence lack of omnipotence and bypasses the role of President of the Republic, a violation, which in itself constitutes a violation of the Constitution. Rather, the Court has based its decision, in violation of international law substantive public.

Naturally, an agreement on the delimitation of borders between the two neighboring countries water is essential and should be accepted by both countries. Clarifying the principles and norms of delimitation, as well as applicable laws, that is the definition, which country would have sovereignty over a particular territory, is an important step to encourage investments undertaken by public and private organizations. However, the Court requires this delimitation, not to violate the territory of Albania, to be just and fair (equitable), and in accordance with principles of international law. The latter is particularly important, because it means that there could be a renegotiation of the same agreement simply fulfilling procedural requirements. Rather, the agreement should change substantially, given that the principles of international maritime law require another delimitation.

The decision of the Constitutional Court, is a decision that will constitute an important contribution, not only in the domestic law, but will be cited and mentioned treaties and reference sources of international law of the sea, worldwide.

\section{Conclusions}

\subsection{What lacks Albania-Greece Agreement?}

The Albania-Greece Agreement lacked, omnipotence negotiators, the conclusion of the Constitutional Court declared unconstitutional the above agreement, unanimous in its decision. ${ }^{6}$

An agreement so important that concerns the territory of the Republic of Albania, should be transparent to the public, to the extent not violate state secret, and was the result of many discussions, hearings, studies of similar cases between negotiators and it should not be achieved in a short time. Suffice it to mention that the US signed the UNCLOS after 27 years.

The agreement had technical shortcomings; the most special is the lack of maps with data relevant coordination, which in its design phase.

I think there are shortcomings encountered in the arguments used. By negotiating group could have been used as evidence some of the main articles of the annexes of the UNCLOS Convention, namely:

Article 15: Delimitation of the territorial sea between States with opposite or adjacent coasts

Where the coasts of two States are opposite or adjacent to each other, neither of the two States is entitled, failing agreement between them to the contrary, to extend its territorial sea beyond the median line every point of which is equidistant from the nearest points on the baselines from which the breadth of the territorial seas of each of the two States is measured. The above provision does not apply, however, where it is necessary by reason of historic title or other special circumstances to delimit the territorial seas of the two States in a way which is at variance therewith.

Article 13: Low-tide elevations

1. A low-tide elevation is a naturally formed area of land which is surrounded by and above water at low tide but submerged at high tide. Where a low-tide elevation is situated wholly or partly at a distance not exceeding the 
breadth of the territorial sea from the mainland or an island, the low-water line on that elevation may be used as the baseline for measuring the breadth of the territorial sea.

2. Where a low-tide elevation is wholly situated at a distance exceeding the breadth of the territorial sea from the mainland or an island, it has no territorial sea of its own.

Article 7. Straight baselines:

1. In localities where the coastline is deeply indented and cut into, or if there is a fringe of islands along the coast in its immediate vicinity, the method of straight baselines joining appropriate points may be employed in drawing the baseline from which the breadth of the territorial sea is measured.

2. Where because of the presence of a delta and other natural conditions the coastline is highly unstable, the appropriate points may be selected along the furthest seaward extent of the low-water line and, notwithstanding subsequent regression of the low-water line, the straight baselines shall remain effective until changed by the coastal State in accordance with this Convention.

3. The drawing of straight baselines must not depart to any appreciable extent from the general direction of the coast, and the sea areas lying within the lines must be sufficiently closely linked to the land domain to be subject to the regime of internal waters.

4. Straight baselines shall not be drawn to and from low-tide elevations, unless lighthouses or similar installations which are permanently above sea level have been built on them or except in instances where the drawing of baselines to and from such elevations has received general international recognition.

5. Where the method of straight baselines is applicable under paragraph 1, account may be taken, in determining particular baselines, of economic interests peculiar to the region concerned, the reality and the importance of which are clearly evidenced by long usage.

6. The system of straight baselines may not be applied by a State in such a manner as to cut off the territorial sea of another State from the high seas or an exclusive economic zone.

Article 14 Combination of methods for determining baselines

The coastal State may determine baselines in turn by any of the methods provided for in the foregoing articles to suit different conditions.

Article 121 Regime of islands

1. An island is a naturally formed area of land, surrounded by water, which is above water at high tide.

2. Except as provided for in paragraph 3 , the territorial sea, the contiguous zone, the exclusive economic zone and the continental shelf of an island are determined in accordance with the provisions of this Convention applicable to other land territory.

3. Rocks which cannot sustain human habitation or economic life of their own shall have no exclusive economic zone or continental shelf.

\section{References}

\section{Constitution of Albania}

Law no. 8771, dated April 19, 2001, entered into force on April 19, 2001 "For the state border of the Republic of Albania"

Decree no. 4650, dated March 09, 1970 "For the border of Albania".

Law no. 8772, dated April 19, 2001 "For the protection and control of the state border of the Republic of Albania".

Decision no. 15, dated April 15, 2010 of the Constitutional Court of the Republic of Albania

Manual Summary of the Laws of the Sea. Press Centre, military publications and translations. Tirana, 2004

Captain Anastas GOGA. International Law and Maritime Law. 2005

Prof. Arben PUTO. Public International Law. Tirana 2008

Prof. Dr. Zejnullah GRUDA. Public International Law. Pristina, 2009

Convention on the Territorial Sea and the Contiguous Zone. Done at Geneva, 29 April 1958. Entered Into force on 10 September 1964. Convention on the Continental shelf. Done at Geneva, 29 April 1958. Entered Into force on 10 June 1964.

United Nations Convention on the Law of the Sea. Done on 10 December 1982 in Montego Bay, Jamaica. Entered Into force on 16 November 1994. 